\title{
Impact of starvation on fat content and microbial load in edible crickets
}

\section{(Acheta domesticus)}

\author{
A.C. Inácio ${ }^{1,2^{*}}$ iD , I. Vågsholm ${ }^{2}$, A. Jansson ${ }^{3}$, M. Vaga ${ }^{3}$, S. Boqvist ${ }^{2}$ and M.J. Fraqueza ${ }^{1}$ \\ ${ }^{1}$ Faculty of Veterinary Medicine, University of Lisbon, Lisbon, Portugal; ${ }^{2}$ Department of Biomedical Sciences and Veterinary \\ Public Health, Swedish University of Agricultural Sciences, Uppsala, Sweden; ${ }^{3}$ Department of Anatomy, Physiology and \\ Biochemistry, Swedish University of Agricultural Sciences, Uppsala, Sweden; ana.cmra.inacio@gmail.com
}

Received: 27 November 2020 / Accepted: 7 March 2021

(c) 2021 Wageningen Academic Publishers

OPEN ACCESS @O@@ SHORT COMMUNICATION

\begin{abstract}
Interest in insects as food is increasing worldwide, particularly in industrialised countries. Insect-based ingredients are considered novel foods in Europe and there are unresolved concerns regarding food safety. Microbial counts in insects can be high, posing potential health risks to consumers and possibly causing rapid deterioration by spoilage microorganisms. Gut emptying by starvation prior to killing could reduce the microbial load in the insect gut but could also lead to fat loss and lower energy content, reducing the profitability of production. This study evaluated the microbial load (total aerobic counts (TAC), Enterobacteriaceae) in house crickets (Acheta domesticus) starved for $0 \mathrm{~h}$ (control), $24 \mathrm{~h}$, and $48 \mathrm{~h}$, and the corresponding fat losses. The $24 \mathrm{~h}$ starvation group showed significantly lower $(P=0.004)$ Enterobacteriaceae counts of one $\log \mathrm{cfu} / \mathrm{g}$, but not TAC, (compared to the control group). TAC was significantly increased $(P=0.002)$, by almost one $\log \mathrm{cfu} / \mathrm{g}$ in the $48 \mathrm{~h}$ starvation group compared with the control. Sex of the insects had no significant effect on microbial numbers $(P=0.72$ and $P=0.46$ for TAC and Enterobacteriaceae, respectively). Starvation for $24 \mathrm{~h}$ decreased fat content in crickets $(P=0.02)$, indicating potential production losses. This shows that starvation is not an effective method for reducing microbial loads in edible crickets.
\end{abstract}

Keywords: insects as food, food safety, starvation, plate count, lipid content

\section{Introduction}

Edible insects are being promoted as an alternative source of protein, due to environmental benefits, compared with some conventional animal production systems, deriving from potentially higher feed conversion ratios and higher proportion of edible weight (Oonincx et al., 2015; Van Huis, 2013). Within the European Union, insects are considered as novel foods (Regulation (EU) No. 2015/2283) (EU, 2015). Although no microbiological criteria specific for edible insects have yet been developed in the EU, it has been suggested to use those intended for meat and shellfish in Commission Regulation (EC) No. 2073/2005 of 15 November 2005 on microbiological criteria for foodstuffs (IPIFF, 2019). More precisely, to use the food safety acceptance criteria laid down in Annex 1-1.2. (Listeria monocytogenes in ready-to-eat foods), 1.16. (Salmonella in cooked crustaceans and molluscan shellfish,), 1.6.
(Salmonella in minced meat and meat preparation made from other species than poultry). Furthermore, it was suggested to use the process hygiene criteria as laid down in 2.1.6. (Escherichia coli and aerobic colony count in minced meat, where out of 5 samples no sample should have more than $500 \mathrm{cfu} / \mathrm{g}$ and at most 2 samples with numbers between 50 and $500 \mathrm{cfu} / \mathrm{g}$ for $E$. coli, and no sample more than 5 million $\mathrm{cfu} / \mathrm{g}$ and at most 2 samples with numbers between 0.5 and 5 million $5 \mathrm{cfu} / \mathrm{g}$ ). Moreover, some European countries such as the Netherlands, Belgium and Finland have already established national criteria on food safety of edible insects (Evira, 2018; FASFC, 2018; NFCPSA, 2014). The European Food Safety Authority (EFSA) has therefore adopted a conservative approach to production and consumption of insects (EFSA, 2015). There are still knowledge gaps regarding food safety of insects, e.g. their microbiological composition (Garofalo et al., 2019). It has been demonstrated that the microbial 
loads in raw edible or processed crickets can be high (Fernandez-Cassi et al., 2018; Grabowski and Klein, 2017a; Vandeweyer et al., 2017). This is important as processed cricket products are usually made from whole insects, including the gastrointestinal tract, which increases the microbial load and may affect food quality, safety, and shelflife. Hence, adequate processing and storing methods must be applied (Klunder et al., 2012). It has been reported that starvation before killing could be one way of emptying the gut, and thus reducing the microbial load in edible crickets. Frequently reported starvation periods include 24 and 48 h (Finke, 2013; Mancini et al., 2019; Wynants et al., 2017). However, starvation may induce significant weight loss and affect the nutritional composition of the insects, as well as increasing cannibalism, resulting in reduced profitability of production (Simpson et al., 2006; Wynants et al., 2017).

This study evaluated the microbial loads in house crickets (Acheta domesticus) after different periods of starvation, and their corresponding fat content.

\section{Material and methods}

\section{Study design and materials}

House crickets were reared in a designated facility at the Department of Anatomy, Physiology and Biochemistry, Swedish University of Agricultural Sciences, under climatecontrolled conditions. Until the start of the experiment, the crickets were kept in plastic boxes $(16.5 \times 14 \times 14 \mathrm{~cm}$ or $28 \times 20 \times 28 \mathrm{~cm}$ ) with a thin steel net fitted in one of the sides to enable ventilation. The boxes were enriched with hiding units made of black piping $(6 \times \varnothing 2.5 \mathrm{~cm})$ (Vaga et al., 2018) and plastic straws $(5 \times \varnothing 0.53 \mathrm{~cm}$ and $5 \times \varnothing 0.8 \mathrm{~cm})$. The temperature was kept at $30 \pm 1{ }^{\circ} \mathrm{C}$ and relative humidity at $45-55 \%$, with a $12 \mathrm{~h}$ lighting regime. Feed was provided $a d$ libitum and consisted of a pelleted feed mixture of oat bran, wheat bran, wheat meal, rapeseed meal, limestone, and a premix of vitamins and minerals (Vaga et al., 2020). Water was given in plastic tubes $(10 \times \varnothing 1.2 \mathrm{~cm})$ that were refilled every 5-10 days. The nymphalid stage lasted about eight weeks and the crickets were collected for analysis within 2-7 days after the last moult to adult stage.

A pilot study was performed to assess whether there was a significant effect of sex of the insects on total aerobic counts (TAC) and Enterobacteriaceae counts. Three replicates (each consisting of 10 crickets) of each sex were starved for $24 \mathrm{~h}$. The crickets were kept and managed as described above.

Next, three groups of crickets were compared: a control group fed ad libitum, which was euthanised by freezing at $-20^{\circ} \mathrm{C}$ at the start of the experiment, and a second and third group initially fed the same diet, but starved for 24 and $48 \mathrm{~h}$, respectively. Crickets from the two study groups were euthanised as described for the control immediately on completion of the experiment. The crickets were stored in the freezer immediately after having been euthanised. The storage time varied between one week and two months.

Eight replicates per group were used for the microbiological analyses, with each replicate containing 7-9 crickets (both females and males). For fat quantification, three replicates of each sex were used, with each replicate consisting of six crickets. In order to monitor mortality and reduce cannibalism during starvation, the crickets were kept in pairs in smaller plastic boxes $(11 \times 7.5 \times 4 \mathrm{~cm}$ and $12.5 \times 12.5 \times 5$ $\mathrm{cm})$. These pairs consisted of one male and one female, to prevent male fighting and to obtain equal numbers of individuals of each sex.

\section{Microbiological analyses}

The samples (7-9 crickets) for microbiological analysis were thawed at room temperature for $30 \mathrm{~min}$., transferred to a Stomacher bag, and crushed in a mortar. After weighing (weight varied between 1.96 and $3.58 \mathrm{~g}$ ), the crushed material was suspended in sterile buffered peptone water (1:9) and homogenised in a Stomacher for $2 \mathrm{~min}$. For analysis of TAC, series of 10 -fold dilution were prepared and 1-ml aliquots of dilutions $10^{-5}$ to $10^{-9}$ were pour-plated onto standard plate count agar (Oxoid, Basingstoke, UK) and homogenised. The methods used were according to the Nordic Committee on Food Analysis (NMKL) method no. 86, $5^{\text {th }}$ edition 2013.

Detection and enumeration of Enterobacteriaceae was performed according to NMKL method No. 144, $3^{\text {rd }}$ edition 2005. From the previous serial dilutions, 1 -ml aliquots of dilutions $10^{-4}$ to $10^{-7}$ were cultured by pour-plating onto violet red bile glucose medium (Becton, Dickson and Company, Sparks Glencoe, MD, USA) and homogenised.

\section{Fat quantification}

Individuals from the fat quantification groups were cut transversely into three to four pieces and weighed. The samples (each containing six crickets) were then freezedried and frozen at $-80^{\circ} \mathrm{C}$. The frozen samples were crushed in a mortar. Total fat content in the cricket material was determined by Soxhlet extraction, using Soxtec/Hydrotec ${ }^{\mathrm{mt}}$ 8000 Total Fat Solution (FOSS, Hillerød, Denmark) and expressed on a dry matter (DM) basis.

\section{Statistical analyses}

For the microbiological analyses, log-transformed data were analysed using Microsoft Office Excel for Windows (Microsoft Corporation by Impressa Systems, Santa Rosa, CA, USA), with a Wilcoxon Signed Rank test and significance level $P<0.05$. Statistical analysis on the fat 
content data was performed in $\mathrm{R}$, using the 'aov' function (Package in R, version 1.4, Wax Begonia: 'stats'; RStudio, Boston, MA, USA factorial analysis of variance (ANOVA) and Tukey's post-hoc analysis, with significance level $P<0.05$.

\section{Results and discussion}

\section{Microbiological analyses}

The pilot study showed that the mean Enterobacteriaceae count was $6.5 \mathrm{log} \mathrm{cfu} / \mathrm{g}$ in female crickets and $6.8 \mathrm{log} \mathrm{cfu} / \mathrm{g}$ in males. The mean TAC level was 7.8 and $7.6 \mathrm{log} \mathrm{cfu} / \mathrm{g}$ in females and males, respectively. There were no significant differences between the sexes for either TAC $(P=0.72)$ or Enterobacteriaceae $(P=0.46)$. Therefore, the samples used for microbiological analyses in the experiment comprised females and males.

The TAC level in the crickets subjected to starvation for $24 \mathrm{~h}$ did not differ from that in the control group $(P=0.08)$, but the level in crickets subjected to $48 \mathrm{~h}$ of starvation was significantly higher $(P=0.002)$ than in the control (Figure 1). There was a significant decrease in the level of Enterobacteriaceae between $0 \mathrm{~h}$ and $24 \mathrm{~h}$ of starvation $(P=0.004)$, but not between $0 \mathrm{~h}$ and $48 \mathrm{~h}(P=0.5)$. Thus the TAC levels in house crickets were not significantly reduced by starvation for $24 \mathrm{~h}$ and $48 \mathrm{~h}$, which is similar to findings by Wynants et al. (2017) for Tenebrio molitor. This might be explained by changes in the gut microbial community caused by reduced feed intake and also by stress, which might favour growth of certain bacteria (Martín-Peláez et al., 2009). The values found for TAC in the control group (no starvation) are comparable to those reported in the literature for fresh A. domesticus (Fernandez-Cassi et al., 2020; Grabowski and Klein, 2017b; Klunder et al., 2012; Vandeweyer et al., 2017). The only significant microbial reduction observed in the present study was in Enterobacteriaceae counts, which decreased with $24 \mathrm{~h}$ of starvation. The differences between this and previous studies may be related to differences in rearing conditions, feed used, and the period of starvation. Typically, in feed and food microbiology, when determining the microbial load of a sample by plate counting as in this study, samples are not frozen but instead analysed in a fresh way. The reason for this is that any freezing treatment will kill part of the micro-organisms present in the sample, which, upon thawing of the sample, are not included in the count. Some micro-organisms may have also become sub-lethally injured after freezing. They will not fully recover during thawing and hence remain uncounted. In our study the freezing step may have affected the living microbiota of the samples and the effect may have been different in samples, explaining the variable Enterobacteriaceae counts. However, freezing could not be avoided in our study, since it was applied as the killing method for the crickets.

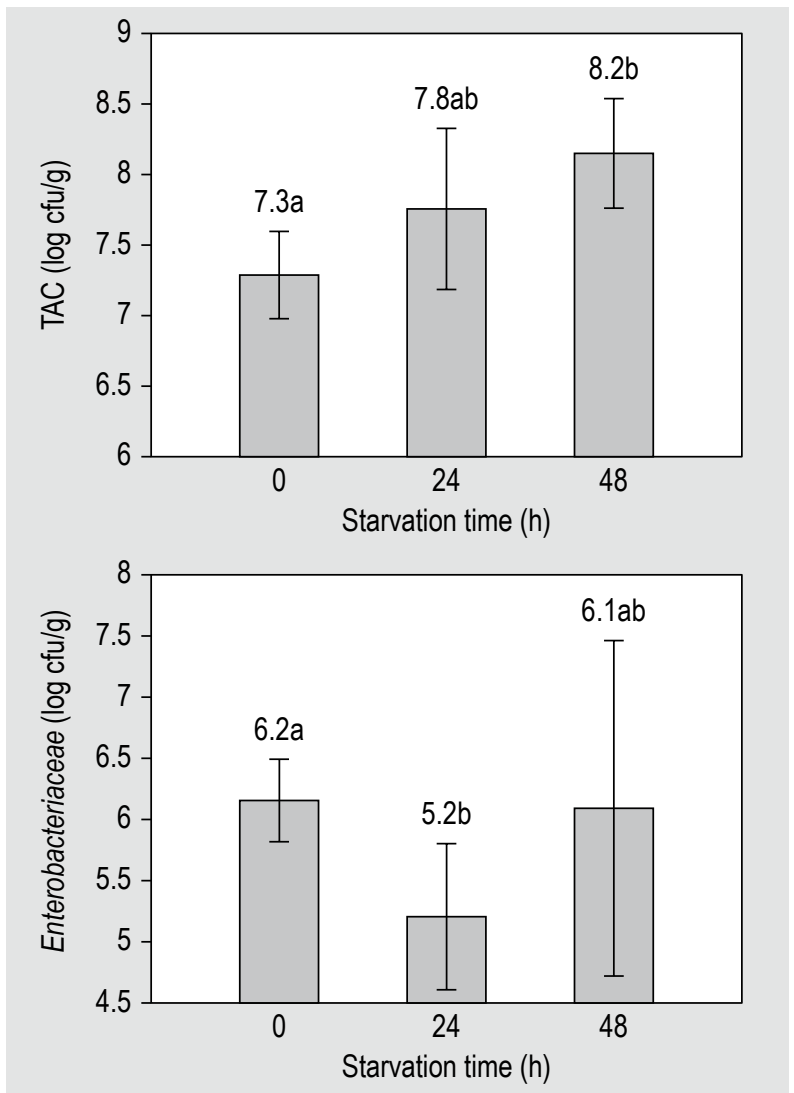

Figure 1. (A) Mean total aerobic counts (TAC; log cfu/g); and (B) mean Enterobacteriaceae counts (log cfu/g) in crickets starved for $0 \mathrm{~h}$ (control), $24 \mathrm{~h}$, and $48 \mathrm{~h}$. Bars indicate standard deviation, means with different letters differ significantly $(P<0.05)$.

\section{Fat quantification}

The mean fat content in all crickets after $24 \mathrm{~h}$ of starvation $(301 \mathrm{~g} / \mathrm{kg} \mathrm{DM})$ was lower $(P=0.02)$ than in control crickets $(357 \mathrm{~g} / \mathrm{kg} \mathrm{DM})$. However, the mean fat content in crickets after $48 \mathrm{~h}$ of starvation $(433 \mathrm{~g} / \mathrm{kg} \mathrm{DM})$ showed a tendency to be higher $(P=0.07)$ than in crickets starved for $24 \mathrm{~h}$ and was similar $(P=0.76)$ to that in control crickets (Table 1$)$. These results for the group starved for $48 \mathrm{~h}$ agree with those of Woodring (1984), who found no reduction in plasma lipid concentration of $A$. domesticus nymphs after $48 \mathrm{~h}$ of starvation. McCue et al. (2015) found that lipid oxidation in crickets increases shortly after onset of fasting and that peak lipid oxidation in adult $A$. domesticus occurs at around $36 \mathrm{~h}$ within the fasting period.

On combining the data from $0 \mathrm{~h}, 24 \mathrm{~h}$, and $48 \mathrm{~h}$ of starvation, it emerged that males had a higher fat content than females $(P=0.015)$. This contradicts findings by Kulma et al. (2019) that females have a higher total fat content. Sex-dependent variation in fat content could be explained by the variation in body composition that occurs with age and developmental stage (Lipsitz and McFarlane, 1971). The exact age (in days) of the crickets in the study by Kulma 
Table 1. Total fat content (g/kg DM) in male and female crickets starved for $0 \mathrm{~h}$ (control), $24 \mathrm{~h}$, and $48 \mathrm{~h}$. Each sample consisted of six crickets. $P$-values for starving indicate differences from the control crickets.

\begin{tabular}{|c|c|c|c|c|c|c|c|}
\hline \multirow[t]{2}{*}{ Starvation period } & \multicolumn{3}{|c|}{ Fat content $(\mathrm{g} / \mathrm{kg} \mathrm{DM}) \pm \mathrm{SD}$} & \multirow[t]{2}{*}{ SEM $^{1}$} & \multicolumn{3}{|l|}{$P$-value } \\
\hline & Males & Females & Mean & & Starving & Sex & Starving $\times$ Sex \\
\hline $\mathrm{Oh}$ & $384 \pm 36$ & $329 \pm 21$ & $357 \pm 40$ & & & & \\
\hline $24 \mathrm{~h}$ & $322 \pm 24$ & $280 \pm 11$ & $301 \pm 28$ & 9.37 & 0.019 & 0.015 & 0.647 \\
\hline $48 \mathrm{~h}$ & $355 \pm 16$ & $333 \pm 27$ & $345 \pm 25$ & & 0.762 & & \\
\hline
\end{tabular}

et al. (2019) is not reported, but the crickets used in the present study had only recently undergone their last moult to adults. Fully mature female ovaries and eggs have high lipid concentrations (Grapes et al., 1989), but the females used in the present analysis were very young, which might have affected their total fat content.

\section{Conclusion}

This study examined the relationships between starvation, microbial load, and fat content of edible crickets. The results were somewhat contradictory as regards the effectiveness of using starvation to reduce levels of TAC and Enterobacteriaceae. There was an initial reduction in Enterobacteriaceae, but longer periods of starvation did not reduce levels of bacteria in the gut of crickets and had no clear effect on fat content in the crickets. Therefore, this small study does not support the use of starvation to reduce microbial counts in edible insects. Larger studies are needed to confirm these findings.

\section{Conflict of interest}

The authors declare no conflict of interest.

\section{References}

European Food Safety Authority (EFSA), 2015. Risk profile related to production and consumption of insects as food and feed. EFSA Journal 13: 4257.

European Union (EU), 2015. Regulation (EU) 2015/2283 of the European Parliament and of the Council of 25 November 2015 on novel foods, amending Regulation (EU) No 1169/2011 of the European Parliament and of the Council and repealing Regulation (EC) No 258/97 of the European Parliament and of the Council and Commission Regulation (EC) No 1852/2001. Official Journal of the European Union L 327: 1-22.

Federal Agency for the Safety of the Food Chain (FASFC), 2018. Circulaire relative à lélevage et à la commercialisation d'insectes et de denrées à base d'insectes pour la consommation humaine. FASFC, Brussels, Belgium.
Fernandez-Cassi, X., Söderqvist, K., Bakeeva, A., Vaga, M., Dicksved, J., Vagsholm, I., Jansson, A. and Boqvist, S., 2020. Microbial communities and food safety aspects of crickets (Acheta domesticus) reared under controlled conditions. Journal of Insects as Food and Feed 6(4): 429-440.

Fernandez-Cassi, X., Supeanu, A., Jansson, A., Boqvist, S. and Vagsholm, I., 2018. Novel foods: a risk profile for the house cricket (Acheta domesticus). EFSA Journal 16: e16082. https://doi. org/10.2903/j.efsa.2018.e16082

Finke, M.D., 2013. Complete nutrient content of four species of feeder insects. Zoo Biology 32: 27-36.

Finnish Food Safety Authority Evira (Evira), 2018. Insects as food. Evira, Helsinki, Finland. Available at: https://www.ruokavirasto.fi/ globalassets/tietoa-meista/asiointi/oppaat-ja-lomakkeet/yritykset/ elintarvikeala/alkutuotanto/eviran_ohje_10588_2_uk.pdf

Garofalo, C., Milanović, V., Cardinali, F., Aquilanti, L., Clementi, F. and Osimani, A., 2019. Current knowledge on the microbiota of edible insects intended for human consumption: a state-of-the-art review. Food Research International 125: 108527.

Grabowski, N.T. and Klein, G., 2017a. Microbiology of cooked and dried edible Mediterranean field crickets (Gryllus bimaculatus) and superworms (Zophobas atratus) submitted to four different heating treatments. Food Science and Technology International 23: 17-23.

Grabowski, N.T. and Klein, G., 2017b. Microbiology of processed edible insect products - results of a preliminary survey. International Journal of Food Microbiology 243: 103-107.

Grapes, M., Whiting, P. and Dinan, L., 1989. Fatty acid and lipid analysis of the house cricket, Acheta domesticus. Insect Biochemistry 19: 767-774.

International Platform of Insects for Food and Feed (IPIFF), 2019. Guide of good hygiene practices for European Union (EU) producers of insects as food and feed. IPIFF, Brussels, Belgium, pp. 6-94.

Klunder, H.C., Wolkers-Rooijackers, J., Korpela, J.M. and Nout, M.J.R., 2012. Microbiological aspects of processing and storage of edible insects. Food Control 26: 628-631. https://doi.org/10.1016/j. foodcont.2012.02.013

Kulma, M., Kouřimská, L., Plachý, V., Božik, M., Adámková, A. and Vrabec, V., 2019. Effect of sex on the nutritional value of house cricket, Acheta domestica L. Food Chemistry 272: 267-272. 
Lipsitz, E.Y. and McFarlane, J.E., 1971. Analysis of lipid during the life cycle of the house cricket, Acheta domesticus. Insect Biochemistry 1: 446-460.

Mancini, S., Paci, G., Ciardelli, V., Turchi, B., Pedonese, F. and Fratini, F., 2019. Listeria monocytogenes contamination of Tenebrio molitor larvae rearing substrate: preliminary evaluations. Food Microbiology 83: 104-108. https://doi.org/10.1016/j.fm.2019.05.006

Martín-Peláez, S., Peralta, B., Creus, E., Dalmau, A., Velarde, A., Pérez, J.F., Mateu, E. and Martín-Orúe, S.M., 2009. Different feed withdrawal times before slaughter influence caecal fermentation and faecal Salmonella shedding in pigs. The Veterinary Journal 182: 469-473

McCue, M.D., Guzman, R.M., Passement, C.A. and Davidowitz, G., 2015. How and when do insects rely on endogenous protein and lipid resources during lethal bouts of starvation? A new application for 13C-breath testing. PLoS ONE 10: e0140053. https://doi. org/10.1371/journal.pone.0140053

Netherlands Food and Consumer Product Safety Authority (NFCPSA), 2014. Advisory report on the risks associated with the consumption of mass reared insects. NFCPSA, Utrecht, the Netherlands.

Oonincx, D.G.A.B., Van Broekhoven, S., Van Huis, A. and Van Loon, J.J.A., 2015. Feed conversion, survival and development, and composition of four insect species on diets composed of food byproducts. PLoS ONE 10: e0144601.

Simpson, S.J., Sword, G.A., Lorch, P.D. and Couzin, I.D., 2006. Cannibal crickets on a forced march for protein and salt. Proceedings of the National Academy of Sciences of the USA 103: 4152-4156.
Vaga, M., Berggren, Å., Pauly, T. and Jansson, A., 2020. Effect of red clover-only diets on house crickets (Acheta domesticus) growth and survival. Journal of Insects as Food and Feed 6(2): 179-189.

Vaga, M., Gustafsson, E. and Jansson, A., 2018. Evaluation of reusable hiding units for rearing house crickets (Acheta domesticus). In: Book of abstracts of the $69^{\text {th }}$ annual meeting of the European Federation of Animal Science. Vol. 24. Dubrovnik, Croatia, 27-31 August 2018. Wageningen Academic Publishers, Wageningen, the Netherlands, pp. 470.

Van Huis, A., 2013. Potential of insects as food and feed in assuring food security. Annual Review of Entomology 58: 563-583.

Vandeweyer, D., Crauwels, S., Lievens, B. and Van Campenhout, L., 2017. Microbial counts of mealworm larvae (Tenebrio molitor) and crickets (Acheta domesticus and Gryllodes sigillatus) from different rearing companies and different production batches. International Journal of Food Microbiology 242: 13-18.

Woodring, J.P., 1984. The effect of starving versus fasting on blood composition on larval house crickets. Journal of Insect Physiology 30: 251-255.

Wynants, E., Crauwels, S., Lievens, B., Luca, S., Claes, J., Borremans, A., Bruyninckx, L. and Van Campenhout, L., 2017. Effect of post-harvest starvation and rinsing on the microbial numbers and the bacterial community composition of mealworm larvae (Tenebrio molitor). Innovative Food Science and Emerging Technologies 42: 8-15. 
